\title{
A METHOD FOR ESTIMATING INSTANTANEOUS PULMONARY CAPILLARY BLOOD FLOW IN MAN *
}

\author{
By KARLMAN WASSERMAN $\dagger$ AND JULIUS H. COMROE, JR.
}

(From the Cardiovascular Research Institute, University of California School of Medicine, San Francisco, Calif.)

(Submitted for publication June 15, 1961 ; accepted August 31, 1961)

The use of soluble, "inert" gases to measure cardiac output dates from 1910 when Bornstein (1) used nitrogen as the test gas. He stated the principle that, if a gas does not react chemically with blood, its rate of absorption is proportional to the quantity of blood flowing through the pulmonary capillary bed. If the solubility coefficient of the gas in blood and the difference between the partial pressures of the gas in alveolar air and in pulmonary arterial blood are known, and if equilibrium of gas tensions across the alveolarcapillary membranes is assumed, the pulmonary capillary blood flow may be calculated.

Krogh and Lindhard (2) improved on Bornstein's method by using nitrous oxide, a much more soluble gas. There followed a series of modifications of gas methods for measuring cardiac output (3-5), but the introduction of the direct Fick technique and the increasing use of methods based on the Stewart-Hamilton indicator dilution principle led to their disuse.

Lee and DuBois (6) used a body plethysmograph (7) to measure the instantaneous rate of absorption of nitrous oxide from the lungs in man. This ingenious method has many advantages over the direct Fick and indicator dilution methods because it permits the calculation of instantaneous pulmonary capillary blood flow at frequent intervals without the introduction of needles or catheters into the cardiovascular system. Their method requires of the subject only that he sit in an airtight chamber about the size of a phone booth, take one deep breath of nitrous oxide and then

* Presented at the American Physiological Society meetings, April, 1960, Chicago, Ill. Supported in part by United States Public Health Service Grant H-4029 and by the Office of Naval Research Contract no. Nonr 222 [55].

$\dagger$ United States Public Health Service Postdoctoral Research Fellow. Present address: Dept. of Medicine, Stanford Univ. Medical Center, Palo Alto, Calif. hold his breath at his resting lung volume. As the nitrous oxide molecules leave the gaseous phase and dissolve in the pulmonary capillary blood, the pressure in the closed chamber decreases and the change, measured by a sensitive manometer, can be converted into milliliters of nitrous oxide absorbed. Unfortunately, the Lee-DuBois method has limitations because the requirement of the rigid, upright box prevents the easy use of the method in varied locations such as the operating room, recovery room, or cardiac catheterization laboratory. Further, it cannot be used during change of posture or during any but very light exercise, both because of space limitation and because the output of heat and water vapor into the closed box produces a pressure change which overwhelms the smaller changes due to nitrous oxide absorption.

This paper reports a modification of the method of Lee and DuBois in which the body plethysmograph is not used, thus eliminating many of the disadvantages described above and extending the usefulness of the nitrous oxide method for measuring pulmonary capillary blood flow both for physiological and clinical studies.

\section{METHOD}

In the Lee-DuBois method, a sensitive gauge measures the decrease in gas pressure in an airtight chamber as $\mathrm{N}_{2} \mathrm{O}$ molecules leave the alveolar gas and dissolve in the pulmonary capillary blood. In our system, we have replaced the rigid body plethysmograph with the subject's own thorax (Figure 1). As molecules of $\mathrm{N}_{2} \mathrm{O}$ leave the alveoli and dissolve in the pulmonary capillary blood, alveolar gas pressure decreases and draws gas into the alveoli from the airway-spirometer system; the actual change in alveolar gas pressure is insignificant because of the low impedance of this system. The change in spirometer volume measures directly the exchange of gas molecules between alveoli and blood when the thoracic volume remains constant. An important requirement of the method is therefore that the subject hold his breath at constant thoracic volume so that change in spirometer 


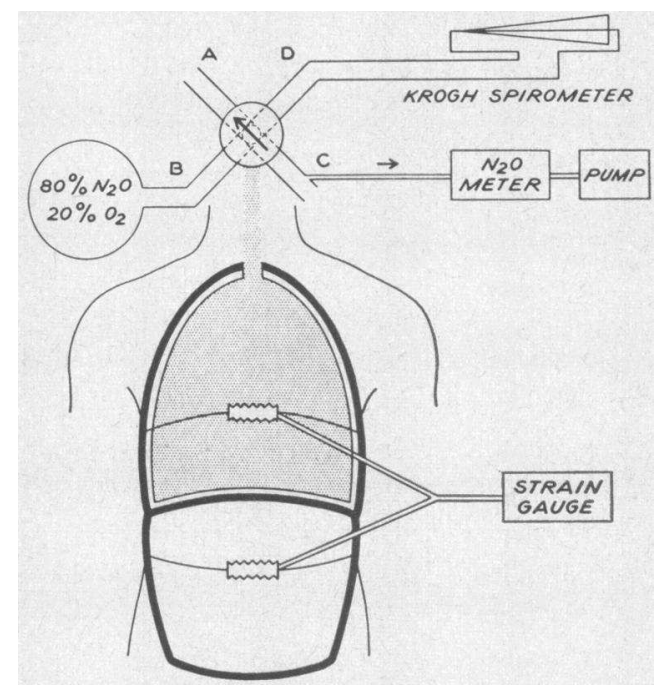

Fig. 1. Schematic diagram of PRocedure for measURING THE RATE OF $\mathrm{N}_{2} \mathrm{O}$ ABSORPTION. The stopcock (arrow) is turned to the 4 outlets in the order indicated by the letters. Pneumographs around the chest and abdomen monitor lung volume changes. See text for details.

gas volume is equal to the net change in alveolar gas exchange. In order to monitor continuously any movement of the chest or abdomen we place two corrugated rubber tubing pneumographs around the chest and upper abdomen of the subject (Figure 1). These are connected to one Statham P23 strain gauge. This system can detect a $1.0-\mathrm{ml}$ change in lung (and thoracic) volume.

The subject breathes through a four-way stopcock ${ }^{1}$ with a 1-inch inner diameter (Figure 1). Depending on the position of the stopcock opening, the subject breathes either: (A) air from the room, (B) 80 per cent $\mathrm{N}_{2} \mathrm{O}$ 20 per cent $\mathrm{O}_{2}$ from a bag, (C) into an outlet tube arranged for sampling expired alveolar gas for analysis of $\mathrm{N}_{2} \mathrm{O}$ concentration, or (D) from a Krogh spirometer. ${ }^{2}$ The procedure is as follows: the subject breathes out to residual volume, inspires air deeply, then exhales to his resting expiratory level (FRC) through outlet $A$ and holds his breath for 15 to 20 seconds; at the beginning of the breath-holding period the stopcock is turned to outlet $\mathrm{D}$ so that the spirometer can record the volume of gas movement in and out of the subject's lungs. This record serves as a control. One to 2 minutes later, the subject repeats the same maneuver except that he inhales the 80 per cent $\mathrm{N}_{2} \mathrm{O}-20$ per cent $\mathrm{O}_{2}$ gas mixture from outlet $\mathrm{B}$. The stopcock is turned to outlet $\mathrm{C}$ when he exhales to the resting lung volume so that the end-tidal alveolar $\mathrm{N}_{2} \mathrm{O}$ concentration can be measured, and then to outlet $\mathrm{D}$ during the 15 to 20 second breath-holding period. After the breath-holding period, the stopcock is again turned to outlet $\mathrm{C}$ and the subject exhales to resid-

\footnotetext{
${ }^{1}$ Hans Rudolph valve, Warren E. Collins, Inc., 555 Huntington Avenue, Boston 15, Mass.

2 Made by Fred J. Christensen, Watertown, Mass.
}

ual volume, and the $\mathrm{N}_{2} \mathrm{O}$ concentration of this second sample of alveolar gas is measured, thus completing the test. The whole procedure may be repeated every 3 minutes.

Expired gas is drawn through the $\mathrm{N}_{2} \mathrm{O}$ analyzer ${ }^{3}$ at a rate of $250 \mathrm{ml}$ per minute by a pump. The sensitivity of the meter is set so that 0 to 100 per cent $\mathrm{N}_{2} \mathrm{O}$ represents $10 \mathrm{~cm}$ on the photographic record. 4 The concentration of $\mathrm{N}_{2} \mathrm{O}$ in alveolar gas is usually between 35 and 50 per cent and can be estimated to within 1 per cent. In studies on expired gas containing $\mathrm{N}_{2} \mathrm{O}$, the meter readings were the same whether the gas entered the analyzer fully saturated or after passage through a drying agent; presumably, water vapor in the expired gas results in an increase in meter reading proportional to the dilution by water vapor. This phenomenon has been described for the $\mathrm{CO}_{2}$ infrared gas analyzer (8). Carbon dioxide, in concentrations usually found in expired gas, had no detectable effect on the meter readings at the sensitivity used in the present study.

The volume of nitrous oxide absorbed at any instant can be determined by subtracting the change in spirometer volume at comparable times during breath-holding after inhalation of air and after inhalation of the nitrous oxide-oxygen gas mixture. A continuous record of change in spirometer volume is obtained by attaching a Honeywell microsyn angular position indicator transducer at the fulcrum of the spirometer. The calibration of this instrument is linear; we use a sensitivity of 6.25 $\mathrm{ml}$ per $\mathrm{cm}$ for low blood flows and $12.5 \mathrm{ml}$ per $\mathrm{cm}$ for high blood flows. The frequency response of the instrument is 15 cps (cycles per second) with a constant amplitude to $10 \mathrm{cps}$.

Figure $2 \mathrm{a}$ shows the changes in spirometer and thoracic volume (pneumograph pressure) and the electrocardiogram during a control period of breath-holding. Both the pneumograph and spirometer tracing show pulsations synchronous with the heart beat, but the thoracic volume remains almost constant from beat to beat at comparable points in the heart cycle. We analyze the spirometer volume change only at those times when the thoracic volume changes less than $1.0 \mathrm{ml}$ between successive heart beats. Figure $2 \mathrm{~b}$ shows the results of the same procedure repeated 1 to 2 minutes later using the nitrous oxideoxygen gas mixture. The thoracic volume again remains constant but the spirometric tracing shows a rapid decrease in volume, again with superimposed fluctuations synchronous with the heart beat.

The alveolar nitrous oxide concentration $\left(\mathrm{F}_{\mathrm{AN}_{\mathrm{N}: 0} \mathrm{O}}\right)$ at any instant during breath-holding is estimated from a semilogarithmic plot constructed from the concentrations of $\mathrm{N}_{2} \mathrm{O}$ measured at the beginning and end of breathholding (Figure 2b) ; the decrease in alveolar $\mathrm{N}_{2} \mathrm{O}$ has been shown to be exponential (9). (The rate of change in alveolar nitrous oxide concentration during the breathholding period is of such small magnitude, however, that an arithmetic plot can be used for calculating cardiac output in resting man.) To minimize the possibility

\footnotetext{
3 Beckman Instruments, Palo Alto, Calif.

${ }^{4}$ Electronics for Medicine, White Plains, N. Y.
} 

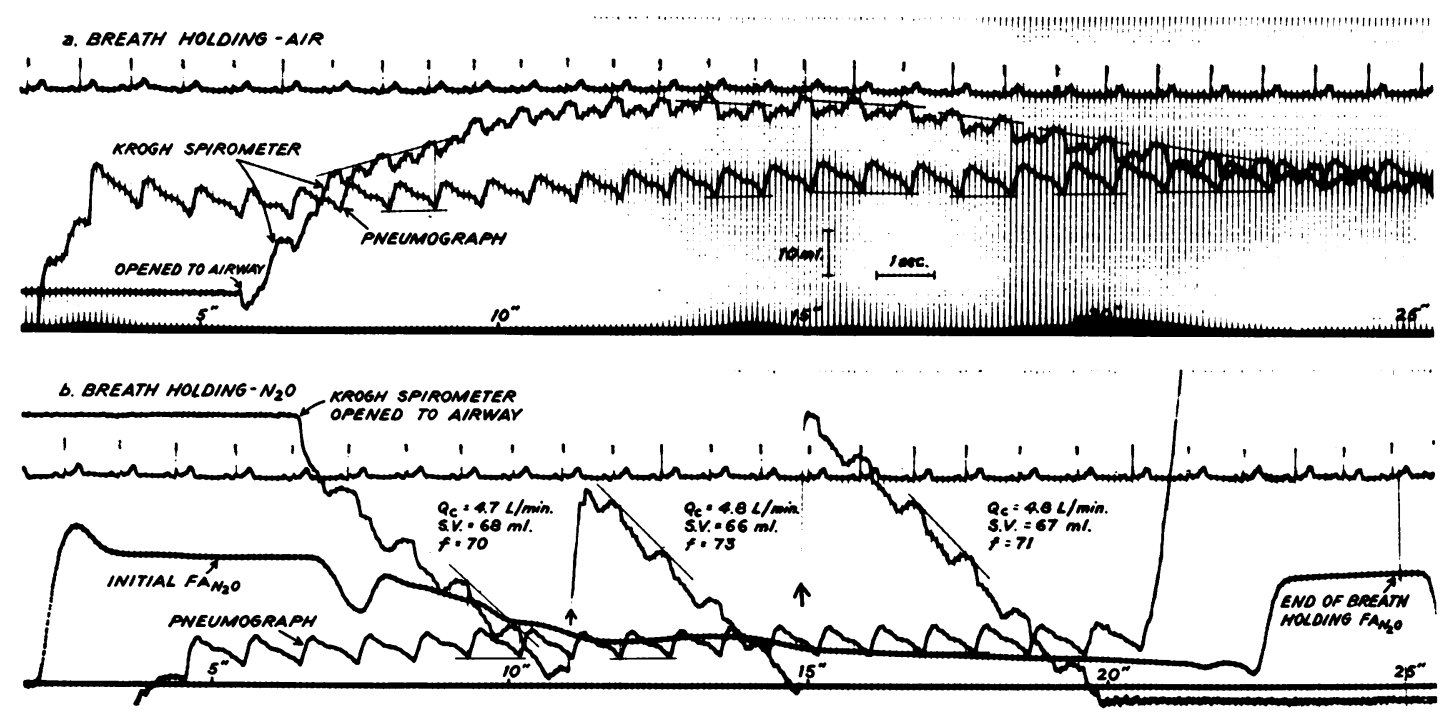

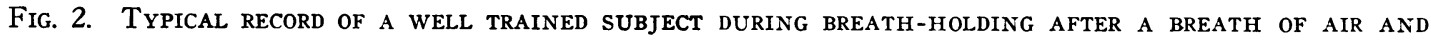
$\mathrm{N}_{2} \mathrm{O}$. The horizontal lines drawn on the pneumograph tracing indicate that breath-holding was precise. Lines perpendicular to the $\mathrm{x}$-axis are drawn to the spirometar tracing through corresponding points of successive heart beats. The slope drawn through the points where the perpendiculars intercept the spirometer tracing is a measure of the net rate of gas exchange. The spirometer tracing was replaced in position when it reached the lower edge of the record in $2 \mathrm{~b}$ (arrows).

that the plateau concentrations do not reflect the patient's true alveolar $\mathrm{N}_{2} \mathrm{O}$, only patients with normal inspired gas distribution were studied.

Calculations. Pulmonary capillary blood flow is calculated, using the Bornstein modification (1) of the Fick principle, assuming that there is no significant recirculation (no nitrous oxide in the pulmonary arterial blood) and that the $\mathrm{P}_{\mathrm{N}_{2} \mathrm{O}}{ }^{5}$ in the blood leaving any pulmonary capillary is the same as that in the corresponding alveolus at any instant in time. The formula used is:

$$
Q_{c}=\frac{\dot{V}_{\mathrm{N}_{2} \mathrm{O}} \times f}{[\alpha]^{370}{ }_{\mathrm{N}_{2} \mathrm{O}} \times \mathrm{FA}_{\mathrm{An}_{2} \mathrm{O}}}
$$

where $\dot{Q}_{c}=$ pulmonary capillary blood flow per minute, $\mathrm{V}_{\mathrm{N}: 0}=$ the volume of nitrous oxide absorbed per heart beat, $f=$ heart rate per minute, and $\mathrm{F}_{\mathrm{A}_{\mathrm{N}_{2} \mathrm{O}}}=$ the nitrous oxide concentrations in alveolar gas expressed as the fraction of 1 standard atmosphere $(760 \mathrm{~mm} \mathrm{Hg})$. We multiply the $\mathrm{N}_{2} \mathrm{O}$ meter readings by 0.925 to correct for the dry gas concentrations recorded and the $750 \mathrm{~mm} \mathrm{Hg}$ ambient pressure of our laboratory. Also, $[\alpha]_{\mathrm{N}_{2} 0^{370}}=$ solubility coefficient of nitrous oxide in blood at $37^{\circ} \mathrm{C}$ and 1 standard atmosphere pressure $=0.47 \mathrm{ml}$ nitrous oxide per $\mathrm{ml}$ blood (10).

Nitrous oxide uptake per beat $\left(\mathrm{V}_{\mathrm{N}_{2} \mathrm{O}}\right)$ is measured as the algebraic difference between the control and experimental slopes of the spirometer tracings for the period of the heart beat. $\vec{V}_{\mathrm{N}_{2} \mathrm{O}}$ so determined is multiplied by a factor of 1.14 before it is substituted into the above equa-

\footnotetext{
${ }^{5} \mathrm{P}=$ tension of the subscript gas.
}

tion for blood flow. This factor includes the following three corrections.

1. A volume of nitrogen approximately equal to 3 per cent of the $\mathrm{N}_{2} \mathrm{O}$ uptake will diffuse from the blood into the alveoli. This is the result of the $\mathrm{P}_{\mathrm{x}_{2}}$ gradient of 250 to $350 \mathrm{~mm} \mathrm{Hg}$ created by taking the breath of the nitrous oxide-oxygen gas mixture. This volume is predictable from the ratio of solubility coefficients of the two gases and must be added to the measured volume of nitrous oxide absorbed.

2. Since the gas in the spirometer is at room temperature $\left(22 \pm 1^{\circ} \mathrm{C}\right)$, the volume must be increased by about 5 per cent to correct it to $37^{\circ} \mathrm{C}$. However, the gas in the spirometer is saturated at room temperature. When the spirometer volume decreases, a volume of water vapor equal to 2 per cent of the volume change condenses. Therefore, the net temperature and water vapor correction is 3 per cent. This is a volume which must be added to the measured volume.

3. Nitrous oxide leaves the pulmonary parenchyma and enters the alveoli or blood as the alveolar nitrous oxide concentration decreases. Based on a nonvascular pulmonary parenchymal volume of $500 \mathrm{ml}$, as estimated by Cander and Forster (9), and a fall of 0.5 per cent in $\mathrm{F}_{\mathrm{A}_{2} \mathrm{O}}$ per second when the $\mathrm{V}_{\mathrm{N}_{2} \mathrm{O}}$ is $15 \mathrm{ml}$ per second, this correction is 8 per cent of $\nabla_{\mathrm{N}_{2} \mathrm{O}}$. This factor will not change with changing blood flow since concentration changes parallel volume changes, the proportion remaining constant. This volume also must be added to the volume change. 


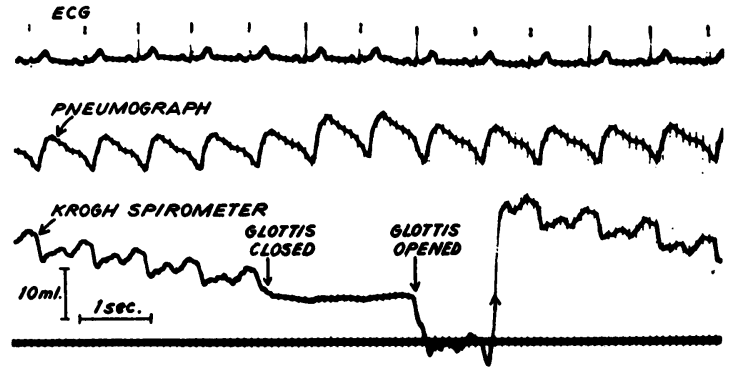

Fig. 3. EfFect of Closing the glottis on the KROGH SPIROMETER AND PNEUMOGRAPH TRACINGS DURING BREATH-HOLDING. When the subject was asked to open his glottis, air moved into the lungs causing the tracing to move to the lower edge of the record. The tracing was then replaced in the position indicated at the arrow.

A critical point in the calculation is that the control and experimental slopes must be measured at the same time interval after the deep breath. Figure 2a shows that during breath-holding after inhalation of air the spirometer volume initially increases. The slope is therefore positive, but it becomes zero between 10 and 15 seconds and then becomes negative. We believe that these changes in slope are caused by a changing respiratory gas exchange ratio ( $R$ ) during breath-holding at the resting lung volume. The initial deep inspiration lowers alveolar $\mathrm{PCO}_{2}$ and causes a steep blood to gas $\mathrm{PCO}_{2}$ gradient and an initial rapid influx of $\mathrm{CO}_{2}$ into alveolar gas. This results in greater $\mathrm{CO}_{2}$ output than $\mathrm{O}_{2}$ intake and a gain in spirometer volume. When the alveolar $\mathrm{PCO}_{2}$ becomes equal to the mixed venous $\mathrm{Pco}_{2}$ (at approximately 15 seconds), the slope becomes negative and then reflects the rate of $\mathrm{O}_{2}$ absorption.

The initial steep positive slope can be reduced by hyperventilating prior to the deep breath and can be eliminated completely by taking a deep breath of 8 per cent $\mathrm{CO}_{2}$ in air instead of air just prior to breath-holding. The slope is not caused by changes in $\mathrm{P}_{\mathrm{H}_{2}} \mathrm{O}$ or in temperature of the gas in the Krogh spirometer because closure of the glottis eliminates the slope (Figure 3). Furthermore, a gradually changing central blood volume cannot contribute significantly to it because posture has no effect on the pattern. Finally, the negative slope can be accounted for quantitatively by the rate of $\mathrm{O}_{2}$ consumption at that time.

To determine the variability of the control slope, the maneuver was repeated six times at 2 -minute intervals in Subject K.W. (Figure 4). The general pattern was the same for each test, but the values calculated during 0 to 10 seconds were more variable and larger than those calculated from points on the slopes after 10 seconds. Because recirculation may occur in significant amounts after 15 seconds, we have selected the period between 10 and 15 seconds after the beginning of breath-holding as the ideal time for analysis. It would be possible to calculate blood flow from the records as early as 8 seconds in those subjects whose initial positive slope is not steep (Figure 4, Subject J.H.).

The control slopes are much more complicated when the body plethysmograph is used $(6,11)$ because of change in temperature and condensation of water vapor on the wall of the chamber; these factors may be so large that the change in $\mathrm{R}$ described above may be completely masked. The magnitude of all three of these variables (temperature, water vapor, gas exchange ratio) depends on the length of time the subject is in the plethysmograph. The length of time between the control and experimental breath-holding periods is critical in plethysmographic measurements because the control pattern changes with time in contrast to the reproducible control pattern obtained by our method.

\section{Criticism of method}

Training of subjects. The method requires breath-holding at constant volume for the time corresponding to 2 successive heart beats. We were successful in training 22 (16 staff and 6 patients) of the 35 subjects ( 21 staff and 14 patients) studied. Closure of the glottis accounted for 10 of the 13 failures and inability to maintain a constant thoracic volume was responsible for 3 failures. A subject who can relax to his resting lung volume (FRC) after the deep inhalation usually performs satisfactorily. A subject who exhales to a lung volume greater or less than FRC frequently

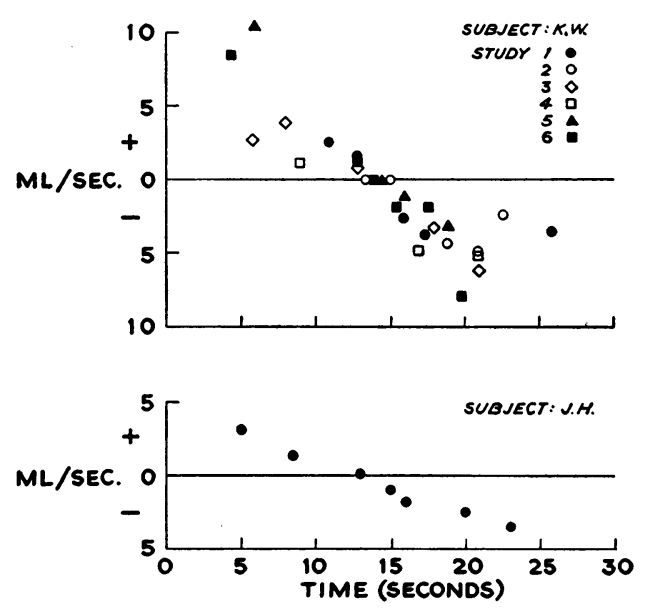

Fig. 4. Net Change IN SPIROMEter volume at DifFERENT TIMES DURING BREATH-HOLDING AT RESTING LUNG VOLUME AFTER A DEEP BREATH OF AIR. LOSS of volume from the spirometer (-); gain in spirometer volume (+). Top, 6 experiments on K.W.; bottom, 1 experiment on J.H. (both in sitting position). The time is measured from the start of the exhalation to FRC after the deep breath of air. See text for interpretation. 
closes his glottis or slowly breathes in or out to FRC during the breath-holding period. The high percentage of failures in patients may be due to the fact that 10 of the 14 had heart disease and some of them were in mild failure.

Patients excluded from the study. Pulmonary capillary blood flow cannot be estimated accurately by this method in subjects who have left-to-right shunts because of the early recirculation of blood containing $\mathrm{N}_{2} \mathrm{O}$ through the defect.

Patients with irregular cardiac rhythms (e.g., atrial fibrillation) cannot be used as subjects because the variable stroke volume during successive beats causes a variable displacement of the thorax and an inconstant pneumograph baseline.

In patients with non-uniform distribution of inspired gas, the assumption that the $\mathrm{N}_{2} \mathrm{O}$ concentration is the same in all alveoli may be erroneous. We use the single breath oxygen test of Comroe and Fowler (12) to detect maldistribution of inspired gas and do not study patients with uneven ventilation.

Recirculation. In two adults without shunts, the pulmonary arterial blood contained less than 2 per cent of the concentration of $\mathrm{N}_{2} \mathrm{O}$ in brachial arterial blood 15 seconds after the breath of 80 per cent $\mathrm{N}_{2} \mathrm{O}$. Sanders and Morrow (13) studied this problem more extensively in patients with and without intracardiac shunts and found similar small values at these early times in the latter group of patients.

Effect of nitrous oxide and the breathing procedure on cardiac output. There is an immediate effect of the breathing procedure itself on heart rate, but the cardiac frequency after 5 seconds of breath-holding is constant and similar to that during quiet breathing prior to the breathing maneuver. There was no significant difference in the heart rates of our subjects during the breathholding period after they inhaled air or the nitrous oxide gas mixture. Measurements of right ventricular output performed for us by Guz, Hoffman, Weirich and Spotts (14) in anesthetized and unanesthetized dogs by means of a modified Kolin electromagnetic flowmeter showed that concentrations of $\mathrm{N}_{2} \mathrm{O}$ similar to those attained in our subjects did not affect stroke volume. Furthermore, the stroke volume did not change significantly from beat to beat in our subjects over

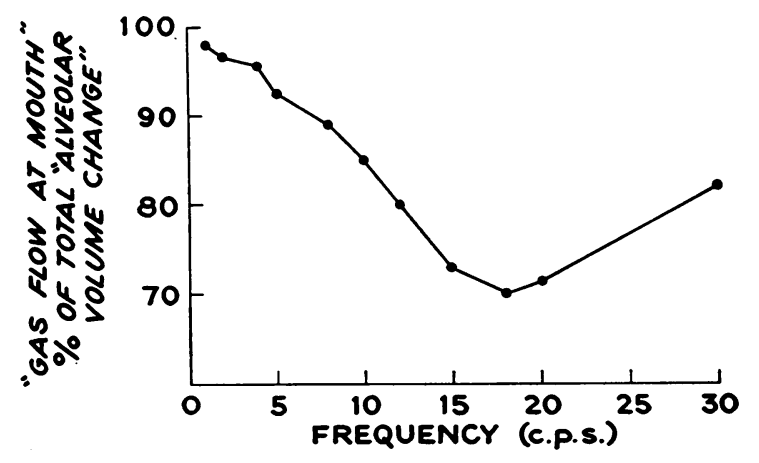

Fig. 5. Per Cent of the total alveolar volume CHANGE RESUlTING FROM GAS EXCHANGE AT THE INDICATED FREQUENCIES THAT WOULD BE DETECTED AT THE MOUTH DURING APNEA, DETERMINED FROM AN ELECTRICAL ANALOG. See text for details.

the period of our measurements ( 8 to 15 seconds from the start of exhalation to FRC).

Sensations after inhalation of nitrous oxide. Most subjects can taste the gas and have a sensation of lightheadedness, accentuation of auditory stimuli, and mild numbness by the time the breathholding is complete, or after the first several breaths of air after breath-holding. After the subject had had several trials, the intensity of these sensations decreased.

Damping of the measured pulsatile blood flow by gas compression and movement of the lung and thoracic cage. To determine the extent to which the events taking place in the alveoli would be reflected at the mouth, an electrical analog was constructed using the values suggested by Clements. Sharp, Johnson and Elam (15) and by DuBois, Brody, Lewis and Burgess (16) for airway, pulmonary, and chest wall compliance, resistance and inertance, and alveolar gas compliance. Figure 5 shows the percentage of the input flow-amplitude that would be detected at the mouth at oscillation frequencies up to $30 \mathrm{cps}$. At $10 \mathrm{cps}, 85$ per cent of the instantaneous flow pattern would be detected at the mouth with only a $4 \mathrm{msec}$ phase lag. Further evidence that the chest wall and lungs do not markedly damp the record of pulsatile pulmonary capillary blood flow is that the cardiac oscillations in the pneumograph record are the same whether subjects perform breath-holding with nitrous oxide or air (Figure 2). However, when the glottis is closed, even the smaller rates of gas displacement created by the 
TABLE I

Resting cardiac output in normal young males and patients

\begin{tabular}{|c|c|c|c|c|c|}
\hline \multicolumn{6}{|c|}{ Normal males } \\
\hline Subject & Age & $\underset{\text { rate }}{\text { Heart }}$ & $\underset{\text { index }}{\text { Cardiac }}$ & $\begin{array}{l}\text { Stroke } \\
\text { index }\end{array}$ & Position and remarks \\
\hline $\begin{array}{l}\text { PS } \\
\text { DT } \\
\text { RY } \\
\text { JH } \\
\text { AG } \\
\text { DD } \\
\text { NS } \\
\text { HR } \\
\text { RN } \\
\text { RL } \\
\text { JG } \\
\text { DF } \\
\text { KW } \\
\text { AC } \\
\text { JC } \\
\text { AN }\end{array}$ & $\begin{array}{l}y r s \\
38 \\
28 \\
32 \\
37 \\
30 \\
35 \\
30 \\
24 \\
22 \\
23 \\
31 \\
38 \\
33 \\
27 \\
26 \\
27\end{array}$ & $\begin{array}{r}70 \\
73 \\
59 \\
65 \\
62 \\
76 \\
100 \\
72 \\
70 \\
68 \\
75 \\
88 \\
97 \\
63 \\
85 \\
60\end{array}$ & $\begin{array}{l}3.7 \\
3.2 \\
3.0 \\
3.2 \\
2.8 \\
3.6 \\
4.1 \\
3.3 \\
4.5 \\
4.1 \\
3.8 \\
3.7 \\
3.9 \\
2.8 \\
3.0 \\
2.8\end{array}$ & $\begin{array}{l}52 \\
44 \\
51 \\
49 \\
45 \\
46 \\
43 \\
46 \\
65 \\
59 \\
51 \\
42 \\
40 \\
44 \\
36 \\
46\end{array}$ & $\begin{array}{l}\text { Supine } \\
\text { Supine } \\
\text { Supine } \\
\text { Supine } \\
\text { Supine } \\
\text { Supine } \\
\text { Supine } \\
\text { Supine } \\
\text { Supine } \\
\text { Supine } \\
\text { Sitting } \\
\text { Sitting } \\
\text { Sitting } \\
\text { Sitting } \\
\text { Sitting } \\
\text { Sitting }\end{array}$ \\
\hline Average & 30 & 74 & $3.4 \pm 0.5^{*}$ & $46 \pm 7^{*}$ & \\
\hline \multicolumn{6}{|c|}{ Patients } \\
\hline $\mathrm{KC} \sigma^{7}$ & 38 & $\begin{array}{l}64 \\
64\end{array}$ & $\begin{array}{l}3.1 \\
2.3\end{array}$ & $\begin{array}{l}50 \\
35\end{array}$ & 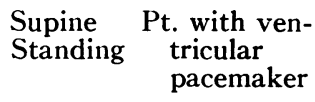 \\
\hline MW & 42 & 81 & 2.8 & 35 & $\begin{array}{l}\text { Supine, nephrotic } \\
\text { syndrome }\end{array}$ \\
\hline TJ $\sigma^{\pi}$ & 21 & 81 & 3.3 & 41 & $\begin{array}{l}\text { Supine, nephrotic } \\
\text { syndrome }\end{array}$ \\
\hline GM $\sigma^{x}$ & 45 & 91 & 2.3 & 25 & $\begin{array}{l}\text { Supine, multiple pul- } \\
\text { monary emboli }\end{array}$ \\
\hline LR $\%$ & 35 & 77 & 2.4 & 30 & Supine, mitral stenosis \\
\hline OS $\quad$ \& & 58 & 104 & 2.6 & 28 & Supine, mitral stenosis \\
\hline
\end{tabular}

$* \pm 1$ standard deviation.

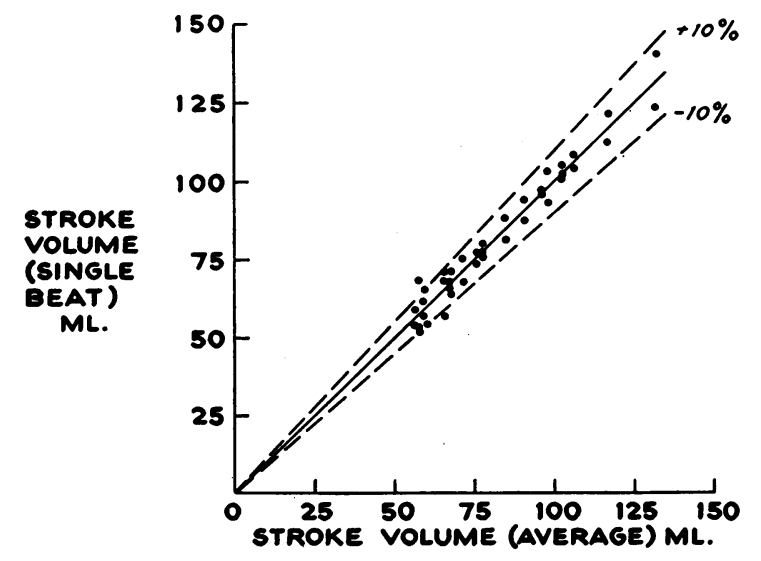

Fig. 6. Stroke volume of 2 to 3 Heart beats MEasURED DURING A SINGLE BREATH-HOLDING PERIOD, PLOTTED AGAINST THEIR AVERAGE. Coefficient of variation $=7.0$ per cent. beating heart (approximately $7 \mathrm{ml}$ per beat) cause larger cardiac oscillations in the pneumograph tracing (Figure 3 ).

\section{RESULTS}

1. Values in resting subjects. Table I summarizes the cardiac and stroke indices of 16 normal subjects and 6 patients, who were 1 hour or more postprandial, and had been resting for 15 minutes or more in the sitting or recumbent position. The values for healthy subjects are similar to those determined by the direct Fick method (17).

2. Reproducibility. We measured two or three stroke volumes in 18 experiments during a single breath-holding period and plotted these values against their mean (Figure 6). We assumed that 
the biological variation would be least during one breath-holding period and therefore the variation from this analysis would represent primarily the error of the method. The coefficient of variation of these data was \pm 7 per cent; only low stroke volumes fell outside of the \pm 10 per cent range. This variation includes the error of : 1 ) estimating constant lung volume, 2) measuring the volume of gas absorbed from the spirometer at the time of constant lung volume, and 3) estimating the air correction. The accuracy of the estimation of alveolar nitrous oxide concentration at different times is subject to little error (see Methods section).

3. Accuracy of the method (Figure 7). Pulmonary capillary blood flow was determined by the nitrous oxide method in supine subjects simultaneously with, or within 1 minute after, the measurement of cardiac output by dye dilution (18) using indocyanine green (19). The dye was injected into an antecubital vein and brachial

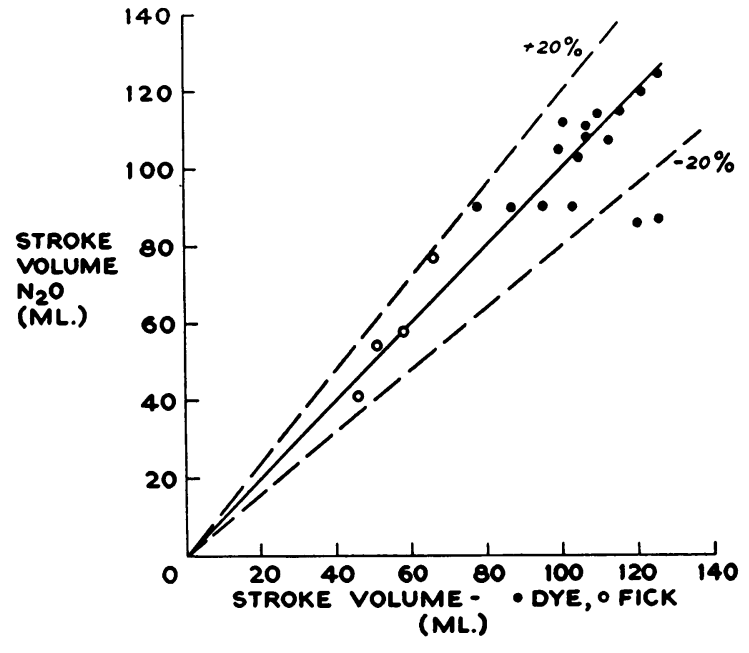

Fig. 7. Stroke volume Determined By THE $\mathrm{N}_{2} \mathrm{O}$ METHOD COMPARED WITH THAT DETERMINED BY THE DYE AND DIRECT FICK METHODS.

artery blood was drawn simultaneously by a constant flow pump through a Colson densitometer

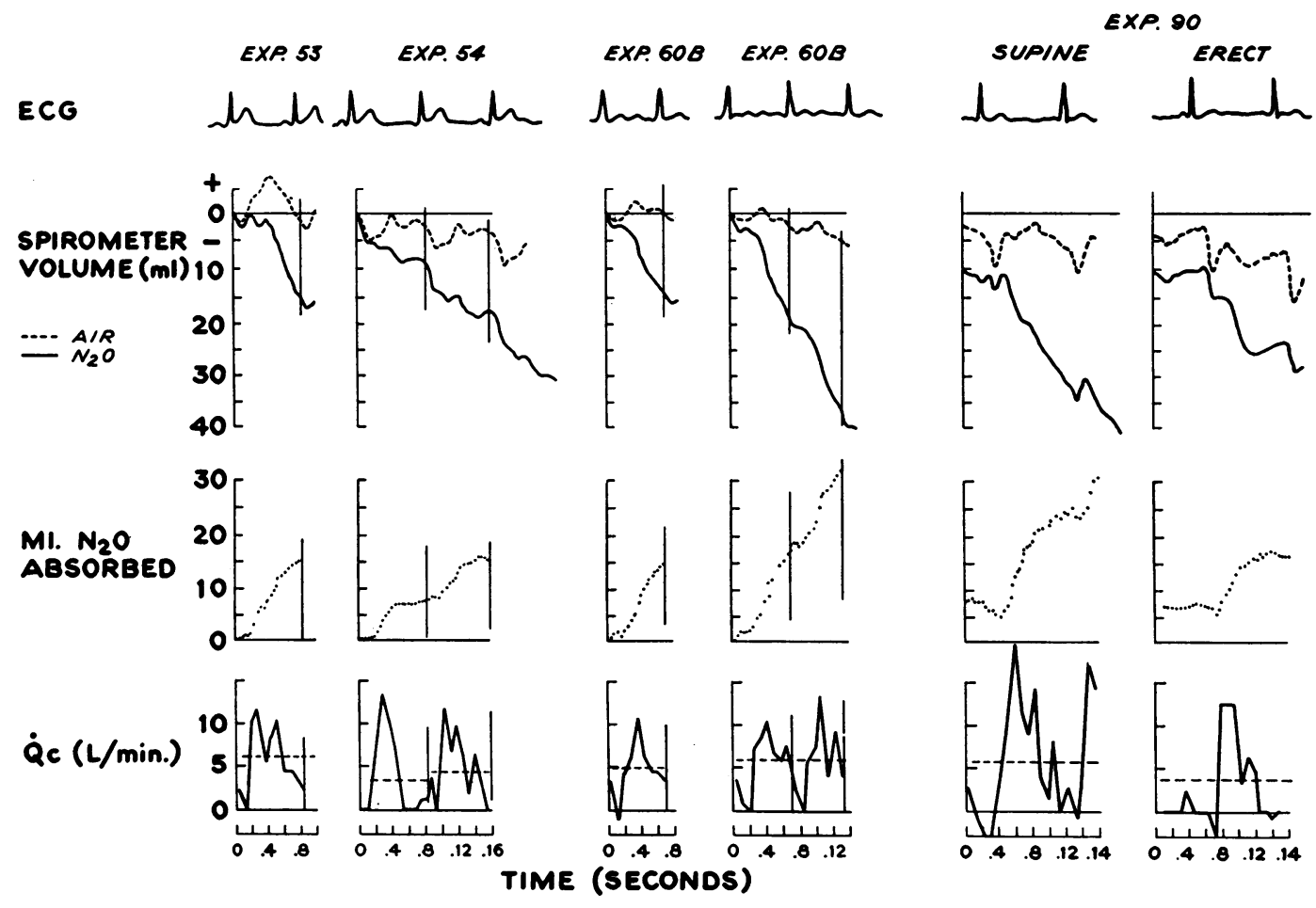

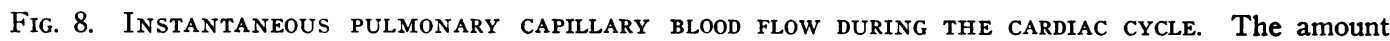
$(\mathrm{ml})$ of $\mathrm{N}_{2} \mathrm{O}$ absorbed during breath-holding (...) is determined by subtracting, every 0.04 sec, the spirometer volume after inhalation of the $\mathrm{N}_{2} \mathrm{O}-\mathrm{O}_{2}$ gas mixture (-) from the spirometer volume after inhalation of air (---). The instantaneous pulmonary capillary blood flow (lowest record) was determined by differentiating the amount $(\mathrm{ml})$ of $\mathrm{N}_{2} \mathrm{O}$ absorbed every $0.08 \mathrm{sec}$ and substituting these values into the blood flow equation (see text). Mean flows are indicated by the dashed line parallel to the $x$-axis. 


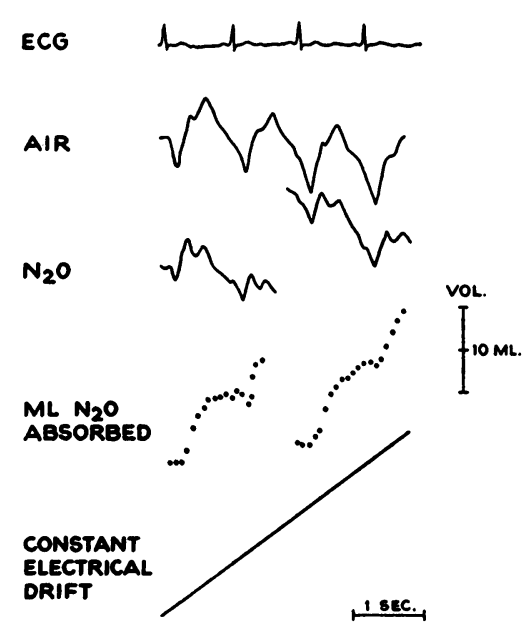

Fig. 9. Modified TeCh NiQUe For MEASURING instantANEOUS $\mathrm{N}_{2} \mathrm{O}$ ABSORPTION. A constant electrical drift (—) is added to the $\mathrm{N}_{2} \mathrm{O}$ signal so as to make the overall $\mathrm{N}_{2} \mathrm{O}$ and air slopes about the same. The difference between the spirometer tracing oscillations during breathholding with air and $\mathrm{N}_{2} \mathrm{O}$ are apparent by inspection. The smaller cardiogenic oscillations seen with $\mathrm{N}_{2} \mathrm{O}$ reflect the pulsatile absorption of $\mathrm{N}_{2} \mathrm{O}$ which is occurring out of phase with the mechanical cardiogenic event. The rate of $\mathrm{N}_{2} \mathrm{O}$ absorption during the cardiac cycle is estimated by adding the difference between the air and $\mathrm{N}_{2} \mathrm{O}$ spirometer tracings to the constant electrical drift.

for recording the arterial dye curve. The stroke volume of the subjects was then increased by administration of $10 \mathrm{mg}$ isoproterenol sublingually and the two methods were repeated.

Nitrous oxide blood flow was estimated 15 seconds after completing the gas collection for oxygen consumption for the direct Fick method in 3 patients ( 2 comparisons in 1 patient) in whom cardiac catheterization was required for diagnostic purposes. The coefficient of variation for all comparisons was 9.6 per cent.

4. Instantaneous pulmonary capillary blood flow during the cardiac cycle. Using our method we have attempted to confirm the observation of Lee and DuBois that $\mathrm{N}_{2} \mathrm{O}$ uptake is pulsatile during the cardiac cycle. We set up rigid criteria for experiments in which we calculated instantaneous blood flow because of artifacts which might influence data derived from subtraction of two records (air and $\mathrm{N}_{2} \mathrm{O}$ ). Our criteria were: 1 ) the heart rate during the two breath-holding periods must be identical ; 2) the glottis must be completely open so as to avoid any damping of the tracings (i.e., the cardiac pulsations in the Krogh spirometer tracing must be uniform and maximum); and 3) measurements must be made at the same time after the start of the two breath-holding periods. The volume of nitrous oxide absorbed (Figure 8 , dotted line) was obtained every 0.04 second by subtracting the volume during the breathholding period with $\mathrm{N}_{2} \mathrm{O}$ (solid line) from the volume during the breath-holding period with air (dashed line). The net rate of $\mathrm{N}_{2} \mathrm{O}$ absorption is not constant. There are consistent flat areas during the first 0.1 to 0.2 second after the QRS complex, followed by a rapid rate of $\mathrm{N}_{2} \mathrm{O}$ absorption, and then a reduced rate. Differentiating the rate of uptake of $\mathrm{N}_{2} \mathrm{O}$ every 0.08 second shows that $\mathrm{N}_{2} \mathrm{O}$ absorption is practically absent during early systole and reaches a maximum at the end of the $T$ wave. These findings are similar in timing and magnitude to the pulsatile pulmonary capillary blood flow described by Lee and DuBois (6). In many cases the pulsatile nature of the pulmonary capillary blood flow is apparent from the record; for example, in the erect posture of experiment 90 the "air" and " $\mathrm{N}_{2} \mathrm{O}$ " tracings were parallel (no gas absorption) for a relatively long period.

More recently, we have modified our method for determining the instantaneous rate of nitrous oxide absorption by adding a constant upward electrical drift to our spirometer signal so that the nitrous oxide and air slopes become about the same (Figure 9). This facilitates the subtraction and makes pulsatile uptake of nitrous oxide in normal subjects apparent merely by observing the difference in area of the cardiogenic pulse in the air and $\mathrm{N}_{2} \mathrm{O}$ tracings. If the uptake of nitrous oxide were nonpulsatile, the areas of the cardiogenic oscillations would be the same on both records and the drift rate would represent the rate of $\mathrm{N}_{2} \mathrm{O}$ absorption. Since the pulsatile $\mathrm{N}_{2} \mathrm{O}$ absorption is out of phase with the cardiogenic oscillation, the area of the cardiogenic oscillation is less in the $\mathrm{N}_{2} \mathrm{O}$ than in the control (air) record.

\section{DISCUSSION}

These results show that it is possible to obtain accurate and reproducible measurements of instantaneous pulmonary capillary blood flow without the use of the body plethysmograph, if one uses sensitive chest and abdominal pneumographs 
to monitor trunk movement and a sensitive spirometer to record the uptake of nitrous oxide. This extends the use of the $\mathrm{N}_{2} \mathrm{O}$ method; e.g., to patients undergoing cardiac catheterization, or to anesthetized patients in whom ventilation is controlled. Because the method involves no discomfort and can be repeated after only a few minutes, it is particularly useful for physiological studies. Although the method is difficult to use during the usual types of exercise because of body movements, we have used it within 15 seconds after the cessation of mild exercise.

Using this independent method, we have confirmed the observation of Lee and DuBois that $\mathrm{N}_{2} \mathrm{O}$ uptake and therefore pulmonary capillary blood flow are pulsatile. However, Rigatto and Fishman (11) believe that the body plethysmograph cannot detect the pulsatile absorption of $\mathrm{N}_{2} \mathrm{O}$ from the lungs because the amplitude of the cardiogenic oscillations after a breath of $\mathrm{N}_{2} \mathrm{O}$ is not consistently larger than that after a breath of air. We believe that Rigatto and Fishman's findings may have resulted from closure of the glottis in some of their subjects. Our experience with the body plethysmograph indicates that the cardiogenic oscillations of a subject during breath-holding are significantly increased when his glottis is closed. This will obscure the changes from pulsatile absorption of $\mathrm{N}_{2} \mathrm{O}$. Even a well trained subject may not know when he closes his glottis. It is essential, when studying instantaneous pulmonary capillary blood flow in the body plethysmograph, that the subject hold his breath with his mouthpiece attached to a pneumotachograph to record cardiogenic gas flow and so be sure that the glottis is completely open during the study. Another possible reason for the differences observed by the two groups is that Rigatto and Fishman's subjects held their breath near the inspiratory capacity, a difficult feat with the glottis open; our subjects and those of Lee and DuBois held their breath at FRC. Blood flow was pulsatile in all of our normal subjects. Pulmonary capillary blood flow may be nonpulsatile in certain disorders of the pulmonary circulation; one of our patients with heart disease did have nonpulsatile flow.

An analysis of the cardiogenic oscillations in the Krogh spirometer and the pneumograph indicates that the displacement of air out of the lungs and the movement of the thoracic cage are in opposite directions; i.e., when air moves into the lungs the chest wall and diaphragm move in, and when air moves out of the lungs the chest and diaphragm move out. Furthermore, when the impedance to air flow out of the lungs is increased by closing the glottis, the cardiogenic oscillations in the pneumograph increase in size (Figure 3 ). When the impedance of the diaphragm is raised by inflating a lower half body " $G$ " suit, the displacement of the air from the mouth with each heart beat increases. These results indicate that the solid mass (blood volume within the thorax) changes during the cardiac cycle. These changes, when timed with the electrocardiogram, show that the thoracic blood volume is largest during late diastole and smallest during late ventricular systole. We have not quantitated the pneumograph to determine the volume displacement of the thoracic cage during the cardiac pulse and hence cannot estimate the absolute change in thoracic blood volume during the cardiac cycle. However, the cardiac pulse recorded by the Krogh spirometer indicates that this volume is at least 5 to $10 \mathrm{ml}$ in the sitting and 10 to $15 \mathrm{ml}$ in the supine posture.

By application of this new $\mathrm{N}_{2} \mathrm{O}$ method, a large amount of physiological and clinical information on pulmonary capillary blood flow may be obtained. It is especially useful in situations in which repeated measurements of pulmonary blood flow are required in subjects in whom cardiac catheterization, venipuncture, and arterial puncture are undesirable. The major limitation of the method is the necessity for training the subject.

\section{SUM MARY}

1. A method is described for measuring instantaneous pulmonary capillary blood flow in man by $\mathrm{N}_{2} \mathrm{O}$ uptake without the use of the body plethysmograph.

2. The method gives reproducible measurements of stroke volume and cardiac output that agree well over a wide range of cardiac outputs with those obtained by the indicator dilution and direct Fick methods.

3. Pulmonary capillary blood flow in man was found to be pulsatile during the cardiac cycle, as described by Lee and DuBois (6). 


\section{ACKNOWLEDGMENTS}

The authors wish to thank Dr. Andre Charlier for making the cardiac output measurements by the indicator dilution technique, that were described in this study. We are also indebted to Dr. Malcolm B. McIlroy for his helpful suggestions during the course of this work and in the preparation of this manuscript.

\section{REFERENCES}

1. Bornstein, A. Eine Methode zur vergleichenden Messung des Herzschlagvolumens beim Menschen. Pflüg. Arch. ges. Physiol. 1910, 132, 307.

2. Krogh, A., and Lindhard, J. Measurement of blood flow through the lungs of man. Skand. Arch. Physiol. 1912, 27, 100.

3. Grollman, A. The Cardiac Output of Man in Health and Disease. Springfield, Ill., Charles C Thomas, 1932.

4. Henderson, Y., and Haggard, H. W. The circulation and its measurement. Amer. J. Physiol. 1925, 73, 193.

5. Asmussen, E., and Nielsen, M. The cardiac output in rest and work determined by acetylene and the dye injection methods. Acta physiol. scand. 1952, 27, 217.

6. Lee, G. de J., and DuBois, A. B. Pulmonary capillary blood flow in man. J. clin. Invest. 1955, 34, 1380.

7. Comroe, J. H., Jr., Botelho, S. Y., and DuBois, A. B. Design of a body plethysmograph for studying cardio-pulmonary physiology. J. appl. Physiol. 1959, 14, 439.

8. Collier, C. R., Affeldt, J. E., and Farr, A. F. Continuous rapid improved $\mathrm{CO}_{2}$ analysis; fractional sampling and accuracy in determining alveolar $\mathrm{CO}_{2}$. J. Lab. clin. Med. 1955, 45, 526.

9. Cander, L., and Forster, R. E. Determination of pulmonary parenchymal tissue volume and pul- monary capillary blood flow in man. J. appl. Physiol. 1959, 14, 541.

10. Kety, S. S. The theory and applications of the exchange of inert gas at the lungs and tissues. Pharmacol. Rev. 1951, 3, 1.

11. Rigatto, M., and Fishman, A. P. The pulsatile nature of the pulmonary capillary blood flow. J. clin. Invest. 1960, 39, 1626.

12. Comroe, J. H., Jr., and Fowler, W. S. Lung function studies: Detection of uneven ventilation during a single breath of oxygen. Amer. J. Med. 1951, 10, 408.

13. Sanders, R. J., and Morrow, A. G. The diagnosis of circulatory shunts by the nitrous oxide test; improvements in technic and methods for quantification of the shunt. Circulation 1958, 18, 856.

14. Guz, A., Hoffman, J., Weirich, W. L., and Spotts, R. R. Measurement of stroke and minute volume in intact conscious dogs with an electromagnetic flowmeter. Physiologist 1960, 3 (no. 3), 70.

15. Clements, J. A., Sharp, J. T., Johnson, R. P., and Elam, J. O. Estimation of pulmonary resistance by repetitive interruption of airflow. J. clin. Invest. $1959,38,1262$.

16. DuBois, A. B., Brody, A. W., Lewis, D. H., and Burgess, B. F., Jr. Oscillation mechanics of lungs and chest in man. J. appl. Physiol. 1956, 8, 587.

17. Thomasson, B. Cardiac output in normal subjects under standard basal conditions; the repeatability of measurements by the Fick method. Scand. J. clin. Lab. Invest. 1957, 9, 365.

18. Hamilton, W. F., Moore, J. W., Kinsman, J. M., and Spurling, R. G. Studies on the circulation. IV. Further analysis of the injection method, and of changes in hemodynamics under physiological and pathological conditions. Amer. J. Physiol. 1932, 99, 534.

19. Symposium on indocyanine green and its clinical applications. Proc. Mayo Clin. 1960, 35, 729. 